\title{
Comparison of Endoscopic Partial Inferior Turbinectomy, Submucosal Radiofrequency Volume Reduction and Inferior Turbinoplasty in Patients with Hypertrophied Inferior Turbinates
}

\author{
MOHAMED E.S. EL-KADY, M.Sc.; EMAD M.K. SHEHATA, M.D.; AHMED S. EL-GUINDY, M.D. and \\ MAGDY E. SAAFAN, M.D. \\ The Department of Otolaryngology, Faculty of Medicine, Tanta University
}

\begin{abstract}
Background: Chronic nasal obstruction is a global health problem affecting large number of population all over the world. Hypertrophy of the Inferior Turbinates (HIT) is one of the leading causes of nasal obstruction. There is no consensus for best method of inferior turbinate volume reduction.

Objective: To compare between the endoscopic Partial Inferior Turbinectomy (PIT), Radiofrequency Assisted Turbinate volume Reduction (RATR) and submucosal resection (SMR) of the inferior turbinate in success of turbinate size reduction with preservation of the physiological functions of the inferior turbinate.
\end{abstract}

Study Design and Setting: A prospective randomized clinical trial in a tertiary care center.

Patients and Methods: 150 patients diagnosed to have (HIT) were randomly selected and allocated into 3 groups for the 3 treatment options. The patients were evaluated preoperatively and post-operatively by a modified Arabic translation of the Sino-Nasal Outcome Test (MA-SNOT16 test) and rigid nasal endoscopy. A $p$-value of less than 0.001 was considered statistically significant.

Results: There was statistically significant improvement in MA-SNOT16 score post-operatively in all groups which continued to be improved more in SMR group. Least operative time was in RATR group and more crustations. Slightly better long term follow-up was observed in SMR group.

Conclusion: There is no consensus on one surgical technique for the inferior turbinate volume reduction. Still there is a need for systematic reviews and meta-analysis to reach the best option.

Key Words: Inferior turbinate - Turbinectomy - Radiofrequency - Turbinoplasty.

Correspondence to: Dr. Mohamed E.S. El-Kady,

The Department of Otorhinolaryngology, Faculty of Medicine, Tanta University

\section{Introduction}

HYPERTROPHY of the Inferior Turbinates (HIT) is one of the leading causes of chronic nasal obstruction which badly affect patients' quality of life. The Inferior Turbinate (IT) is an elongated, scroll-like, paired structure situated at the lateral nasal wall and made of a central core of osseous skeleton and a mucosal layer on each side of the bone [1]. The IT has an important role in the defense of the lungs and the physiology of the nose through temperature regulation and humidification of inspired air, as well as filtration of foreign particles by the mucociliary clearance system [2]

The hypertrophied inferior turbinate can be caused by a wide variety of diseases like chronic rhinitis, allergic rhinitis, chronic non allergic "vasomotor" rhinitis...etc. This condition can be managed by medical treatment like topical corticosteroids and antihistamines for a while. However, these medications may fail to reduce the IT volume so; surgical management should be considered. Although most of these techniques provide satisfactory results for a more or less long period, adverse events are frequently observed post-operatively like bleeding, crustations, pain, hyposmia, and synechia [3]. But no technique is perfect, and each is associated with known short-and long-term complications. The variety of surgical techniques available indicates the lack of consensus on the optimal technique [3]. Hence, it was our study's question to find the better results of the most common techniques in our practice.

\section{Patients and Methods}

A prospective, randomized study was conducted in Otorhinolaryngology Head and Neck Surgery 
Department, Tanta University Hospital from first of May 2015 till the first of November 2016 for one year and half. 150 patients aged from 18 to 45 years old with symptoms and signs of nasal obstruction related to inferior turbinate hypertrophy were randomly selected from the outpatient clinic. Every patient had a card carrying randomized number from 1-150. The cards carry the patient's number and his/her group's letter. So all patients were allocated into three groups (groups A, B and C) of 50 patients each. Group A was treated by Endoscopic Partial Inferior Turbinectomy (PIT), group B was treated by Radiofrequency Assisted Turbinate volume Reduction (RATR) and Group C was treated by Submucosal Resection (SMR).

Study protocol was approved by Institutional Ethical Committee on May 2015 by issue number $30310 / 05 / 15$. All the patients had signed informed written consent to participate in the study and surgical procedures.

All patients included in the study were adults, complaining mainly from chronic nasal obstruction due to HIT not responding to medical treatment for two months. The medical treatment was daily intranasal steroid sprays and systemic antihistaminics for two months.

Patients not willing for surgery, beyond age group, with major nasal pathology like moderate to severe septal deviation, nasal polyps or tumour were excluded from the study. Also Patients with severe bleeding tendency, coagulopathy disorder or contraindication to general anesthesia were also excluded from the study.

HIT was evident on endoscopic examination and computerized topography on nose and paranasal sinuses.

All patients underwent diagnostic protocol which includes usual otolaryngological history taking, complete otorhinolaryngological examination, decongestant test and rigid endoscopic examination. All patients arranged for Turbinate reduction surgery underwent pre-operatively a modified arabic translation of the Sino-Nasal Outcome Test (MA-SNOT 16 test). 4 patients were asked to rate their symptoms from 0-5, where " 0 " means no problem, " 5 " means problem as bad as can be. Results were compared to the post-operative score after 4, 8, 12 months.

\section{Surgical procedures:}

All surgical procedures were done under general anesthesia. Local decongestion was done using cotton pledgets soaked with diluted epinephrine
(1:10000) with normal saline. All procedures were performed with endoscopic guidance using 0 and 30 angled rigid telescope. At the end of the procedure, packing was done using single 10c.m. merocel pack in each nasal cavity for 48 hours.

In group A, PIT was done on both sides. Firstly, the IT was medialized using septal dissector. Secondly, using crushing nasal scissors, the lower third of the posterior two thirds of the IT was removed and the posterior end is subtotal resected. Lastly, lateralization of the remnant part.

In group B, RATR was done using a radiofrequency device (Ellman Surgitron, Radiosurgical Device, Ellmann International) for ablation of the IT using bipolar needle. Radiofrequency energy was delivered to anterior, middle and posterior portions of inferior turbinate for 30-45 seconds with taking great care not to injure the overlying mucosa of the turbinate. The fulguration mode was used and the generator power level was set at grade 5.

In group C, SMR was done bilaterally. After the injection of local anesthesia and decongestant agent, a $0.5 \mathrm{~cm}$ incision was made with a number 15 blade in a vertical manner in the anterior aspect of the inferior turbinate. A submucosal pocket was created with sharp dissection on the medial surface of the bony turbinate. Then the bone is removed with part of submucosal tissue using scissors, hemostasis was done. The incision was not closed.

\section{Outcome measures:}

Intraoperative bleeding was calculated approximately by gathering the amount of lost blood during the operation (blood soaked cotton bledgets which contain around 20c.c. and suctioned volume of blood in isolated small labeled container). Intraoperative bleeding was assessed and graded as follow: Minimal bleeding: It is the puncture bleeding point "just oozing blood". Mild amount of blood loss: Up to 100c.c. Moderate amounts: More than 100c.c. and Less than 300c.c. Severe amounts: More than 300c.c. Calculated approximately by the suction system and blood soaked cotton pledgets.

Subjective follow-up: Through Modified Arabic Sino-Nasal Outcome Test (MA-SNOT) which was recorded at 2 weeks, one month, 4, 8 and 12 months post-operatively.

Simultaneously, nasal endoscopy was done through the follow-up visits. Nasal endoscopy revealed the improvement of the nasal turbinate 
hypertrophy and detected the complications like rehypertrophy or synechia.

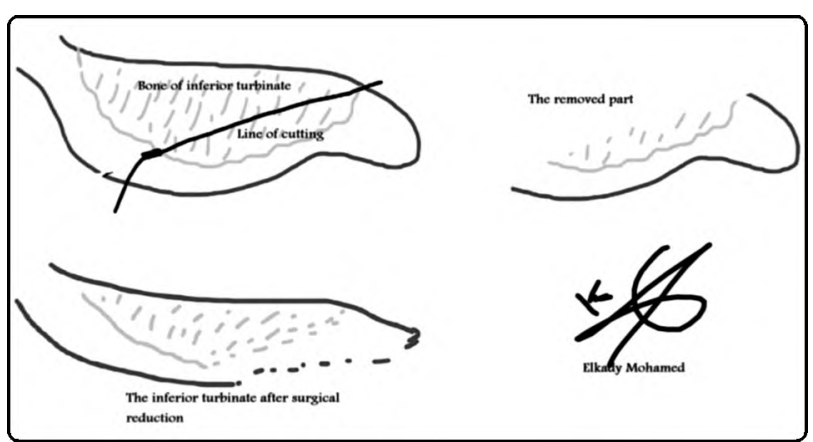

Fig. (1): Diagram showing the partial inferior turbinectomy removed parts.

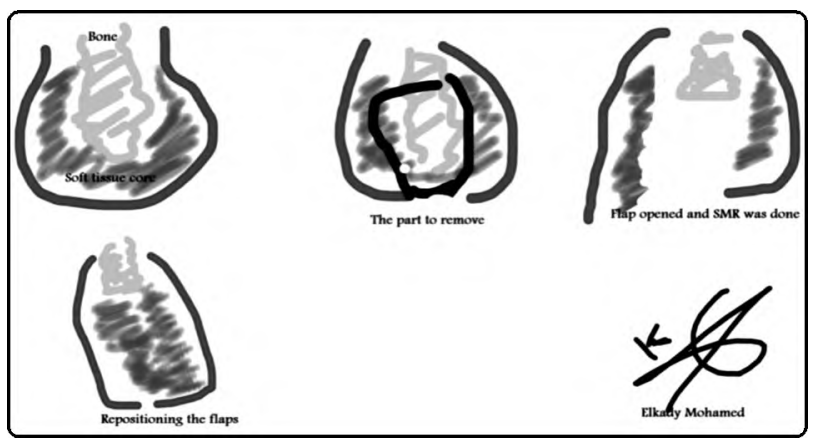

Fig. (2): Diagram showing the submucous resection technique.

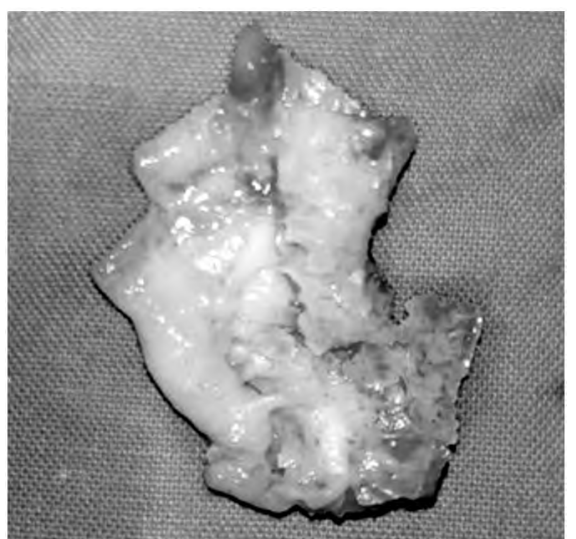

Fig. (3): The excised bony part with small part of mucosal flap in group $\mathrm{C}$.

\section{Results}

There were 73 male patients and 77 females. The age of patients ranged between $18-43$ years old with a mean $26.8 \pm 5.18$.

Pre-operative assessment was done by recording MA-SNOT. As shown in Fig. (4), there was no significant difference between the three groups as regards pre-operative assessment.

Intraoperative assessment: Comparison between amount of bleeding in the three groups was done: In group A, 76\% had moderate amount of bleeding, $16 \%$ had mild amount, $8 \%$ had severe amount of bleeding. In group B, $94 \%$ had just minimal bleeding because of the puncture site of the radiofrequency probe, $6 \%$ had mild amount of bleeding and no patients had moderate or severe bleeding amount. In group C, $84 \%$ had moderate amount of bleeding, $12 \%$ had mild amount, $4 \%$ had severe amount of bleeding.

Operation time was recorded in minutes to show the following findings: In group A, the mean value for operative time was 12.32 minutes ranging from 10 to 14.3 minutes with standard deviation 2.69. In group B, the mean value for operative time was 7.35 minutes ranging from 6 to 10.2 with standard deviation 1.58. In group $\mathrm{C}$, the mean value for operative time was 37.32 minutes ranging from 30 to 48 with standard deviation 4.88 .

Post-operatively, the impact of surgery on the MA-SNOT symptom scores was presented as the difference between the pre-operative and postoperative MA-SNOT scores. Patients had a significant improvement in the total mean MA-SNOT score. In group I, significant improvement from $30.1 \pm 2.48$ pre-operatively to $17.62 \pm 1.83$ four months post-operatively, $16.96 \pm 1.76$ eight months post-operatively and $16.82 \pm 1.72$ after one year. In group II, significant improvement from $30.7 \pm 2.27$ pre-operatively to $19.72 \pm 1.69$ four months postoperatively. After that the overall worsening increased but not to pre-operative level, $22.46 \pm 1.88$ eight months post-operatively and $22.83 \pm 2.44$ after one year. In group III, significant improvement from $30.02 \pm 1.94$ pre-operatively to $17.68 \pm 2.21$ four months post-operatively, then it went back to $18.86 \pm 2.49$ at eight months post-operatively and $18.9 \pm 2.71$ after one year.

Post-operative complication: As regards secondary post turbinectomy bleeding, it was very annoying event to the patient when the patient has severe epistaxis 5-10 days after removal of the pack which needs another packing. In Group I, just one patient from 50 developed secondary post turbinectomy bleeding (2\%). In group II, no patients were recorded to have that kind of bleeding. In group III, also risk of secondary bleeding was $2 \%$ as only one patient developed this bleeding. This means that in our study, the risk of secondary post turbinectomy was the same in group I and group III.

As regard synechia, in group I, just one patient developed synechia, (2\%). In group II, 3 out of 50 
patients developed post-operative synechia, $(6 \%)$. In group III, 4 out of 50 patients developed synechia, (8\%).

As regard crustations: In group A, $84 \%$ of patients had crustations till the second week, 16\% had till the second month and completely disappeared at the fourth month. In group B, $90 \%$ of the patients had crustations till the second month post-operatively, $10 \%$ till the second week and disappeared at the fourth month. In group C, 98\% of the patients had crustations till the second week post-operatively, only $2 \%$ after two months and completely disappeared at the fourth month postoperative follow-up.

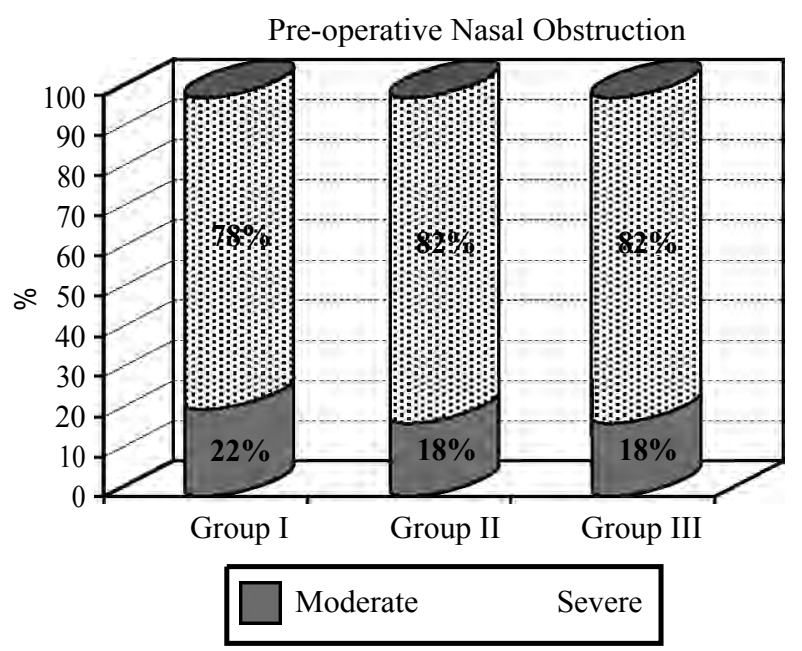

Fig. (4): Comparison between the three groups as regard preoperative nasal obstruction and nasal discharge.

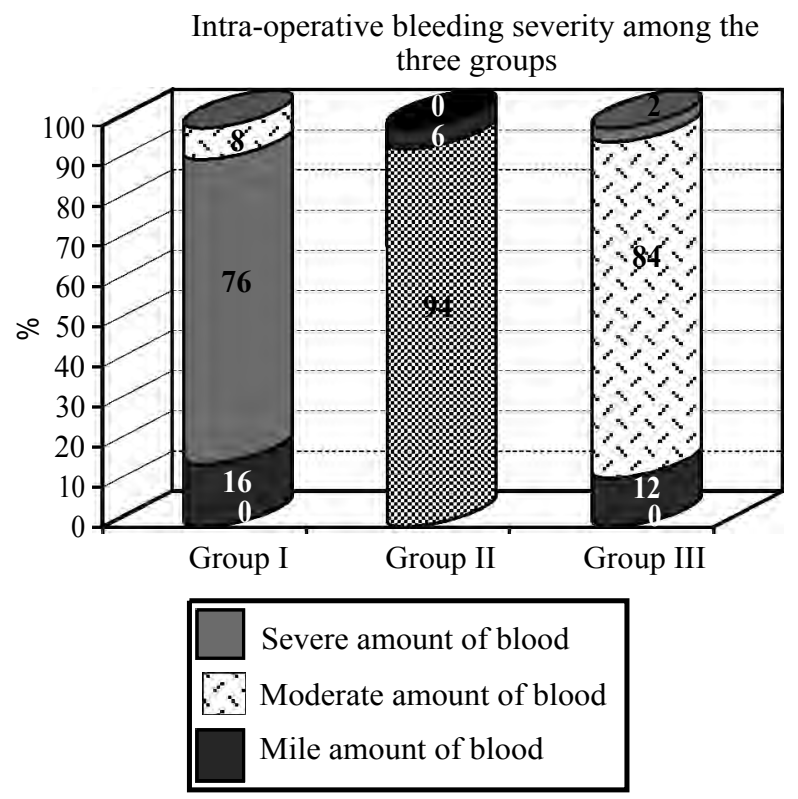

Fig. (5): Comparison between the three groups as regard intraperative bleeding.

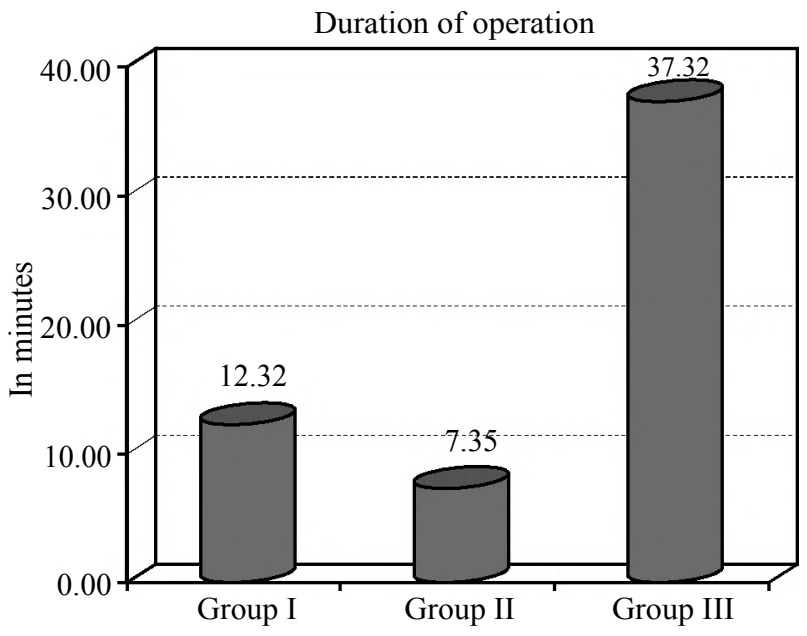

Fig. (6): Comparison between the three groups as regard operative duration.

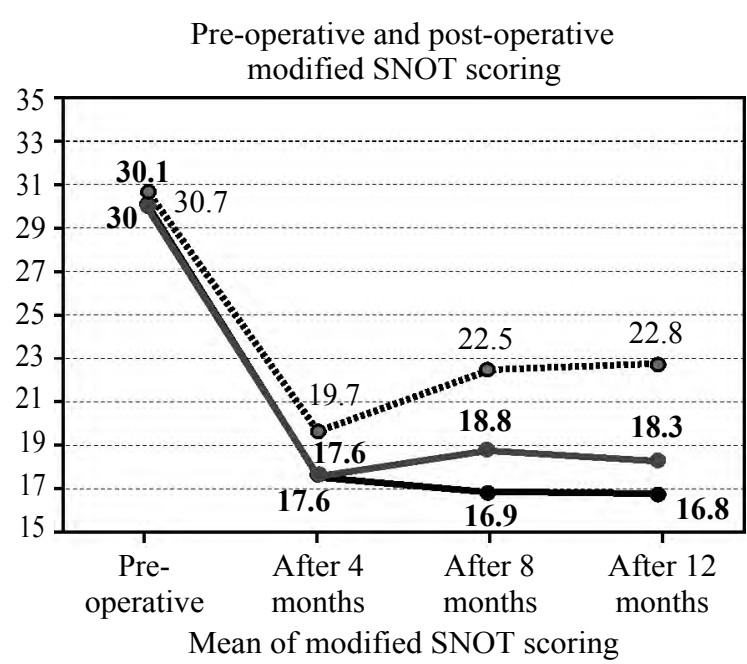

- Group $1 \quad$-..'…" Group $2 \quad$ Group 3

Fig. (7): Pre-operative and post-operative modified SNOT scoring.

Table (1): Comparison between the three groups as regards post-perativesaccarine transit time.

\begin{tabular}{|c|c|c|c|c|c|}
\hline Variables & $\begin{array}{l}\text { Group I } \\
(n=50)\end{array}$ & $\begin{array}{l}\text { Group II } \\
(n=50)\end{array}$ & $\begin{array}{c}\text { Group III } \\
(\mathrm{n}=50)\end{array}$ & $x^{2}$ & $\mathrm{MC}_{p}$ \\
\hline $\begin{array}{l}\text { - Secondary } \\
\text { bleeding. }\end{array}$ & $1(2 \%)$ & $0(0 \%)$ & $1(2 \%)$ & 1.014 & 0.986 \\
\hline \multicolumn{6}{|l|}{$\begin{array}{l}\text { - Crustation } \\
\text { disappeared: }\end{array}$} \\
\hline After 2 weeks & $42(84 \%)$ & $5 \quad(10 \%)$ & 49 (98\%) & 97.049 & $0.001 *$ \\
\hline After 2 months & $8 \quad(16 \%)$ & $45(90 \%)$ & $1 \quad(2 \%)$ & & \\
\hline After 4 months & $0(0 \%)$ & $\mathrm{O}(0 \%)$ & $0(0 \%)$ & & \\
\hline After 8 months & $0 \quad(0 \%)$ & $\mathrm{O}(0 \%)$ & $\mathrm{O}(0 \%)$ & & \\
\hline \multicolumn{6}{|l|}{ - Synechia: } \\
\hline $\begin{array}{l}\text { Post-operative } \\
\text { synechia }\end{array}$ & $1(2 \%)$ & $3(6 \%)$ & $4(8 \%)$ & 1.849 & 0.397 \\
\hline
\end{tabular}




\section{Discussion}

Chronic nasal obstruction is a global health problem affecting large number of population all over the world. Kizilkaya Z. et al., [3] considered HIT to be one of the most frequent causes of chronic nasal obstruction. Treating the HIT is widely accepted to be firstly by medical treatment in the form of nasal steroids and antihistaminics. Failure of the medical treatment takes us to surgery. There are different surgical treatment modalities described in the literature and lots of them are being practiced right now.

Puterman et al., mentioned that these variable techniques have varying degrees of morbidity, success and patient satisfaction. Therefore, the variety of surgical techniques available indicates the lack of consensus on the optimal procedure [5]

In our study we compared between three common modalities in the practice in Egypt. The three mentioned techniques are adequate regarding the socioeconomic state in our society.

Elwany S. and Harrison R. compared four groups: Partial Inferior Turbinectomy (PIT), Inferior Turbinoplasty (IT), Cryoturbinectomy (CT) and Laser Turbinectomy (LT) [6]

Cingi C. et al., compared between two groups: Microdebrider assisted turbinoplasty and radiofrequency assisted inferior turbinoplasty [7]

Other authors discussed only one modality of the treatment like Friedman N.R. et al., [8] who described inferior turbinate reduction using the microdebrider, Garzaro M. et al., [9] who performed only radiofrequency inferior turbinate reduction and Buyuklu F. et al., [10] who discussed turbinate outfracture and its relation to CT scanning.

In a study by Elwany S. and Harrison R., they didn't produce detailed preoperative assessment score but they provided detailed pre-operative data about olfactory threshold and mucociliary clearance [6]. While Passali et al., [11] conducted more and detailed pre-operative assessment as they performed routinely for the patients several investigations like skin prick tests for allergy, active anterior rhinomanometry, acoustic rhinometry, analysis of nasal mucociliary transport time by measurement of the time required for charcoal powder placed on the inferior turbinate to reach the pharynx and measurement of secretory immunoglobulins.

Cavaliere M. et al., [12] compared the effectiveness and safety of radiofrequency turbinoplasty and traditional surgical technique. They have per- formed pre-operative assessment through using a 4-point scale ( 0 , absent; 1 , mild; 2 , moderate; 3 , severe) graded turbinate edema, secretions, and crusts. A standard Visual Analogue Scale (VAS) ranging from 0 (no symptoms) to 10 (the most severe symptoms) was used to assess the subjective symptoms including nasal obstruction, sneezing, itchy nose, hyposmia, headache, snoring, and postoperative pain. Liu, CM. et al., [13] had also used standard VAS.

In this study operative time was a good point for comparing, in group A of (PIT) the mean time was $12.32 \pm 2.69$ ranging from 10 minutes to 14.3 minutes. In group B of (RFTVRT) the mean time was 7.35 \pm 1.58 ranging from 6-10.2 minutes. In group $\mathrm{C}$, Turbinoplasty took longest duration with mean time $37.32 \pm 4.88$ ranging from 30-48 minutes. There is significant difference between the three groups regarding this variable with $p$-value less than 0.001 .

Hamerschmidt R. et al., [14] who compared turbinoplasty surgery efficacy in patients with and without allergic rhinitis; the mean operative time was lower in patients without allergic rhinitis ranging from 5 minutes to more than 10 minutesfor one side.

Marks S. et al., [15] found that operative time was lower in endoscopic turbinoplasty than nonendoscopic by 4 minutes for each side. It seems that there is general agreement that the shortest operation time is radiofrequency volume reduction and the longest is turbinoplasty.

In our study, post-operative subjective assessment was done again by MA-SNOT. After 4 months, nearly all the patients subjectively improved and MA-SNOT score was better with mean difference around 10. This means that the three modalities are successful in improving the complaint of the patient.

After one year post-operatively, group A was better also group $\mathrm{C}$ but group $\mathrm{B}$ was not like scoring at 4 months indicating statistically difference. This means that recurrence is possible with submucosalRART so that long term studies are still wanted.

Elwany S. et al., [6] who compared 4 techniques (PIT, IT, CT, and LT) between 80 patients divided into 4 groups; 20 patients each and he found that turbinoplasty obstruction improvement results were inferior to results of partial inferior turbinectomy that might be due to the massive mucosal excision of the turbinate mucosa in partial inferior turbinectomy. 
Regarding this study's post-operative assessment of subjective outcomes, nasal obstruction is key univariate variable among MA-SNOT different variables.

John Mathai [16] reported that 4\% of the patients operated for partial turbinectomy developed synechiae between nasal septum and lateral wall of nasal cavity treated by releasing it and gelfoam smeared with antibiotic ointment. While we stated in our study $2 \%$ post-operative synechia in partial inferior turbinectomy group, $6 \%$ for radiofrequency group and $8 \%$ for turbinoplasty group. Over all $5 \%$ post - operative synechia in the whole study. Şapçi T. et al., [17] reported no synechia in the all groups of partial turbinectomy, laser ablation and radiofrequency ablation.

John Mathai [16] had reported 2 patients from 75 (around 2.5\%) developed severe epistaxis after removal of the nasal packing for them repacking was required. One patient required blood transfusion. In our study, we didn't find any secondary post turbinectomy bleeding in the second group of radiofrequency ablation turbinoplasty and only 1 patient in each other 2 groups which means that only $2 \%$ significant risk of secondary bleeding in surgical groups PIT and RFTVRT. Şapçi T. et al., reported no uncontrolled bleeding during the operation of partial turbinectomy. Also no postoperative bleeding was reported in the groups of laser ablation or radiofrequency ablation [17] .

In our study, the crustations appeared in all groups during the first 2 weeks post-operatively but it was mild in RFTVRT group. After 2 months post-operatively it was improved in the PIT group from $84 \%$ at 2 weeks to $16 \%$ and in the SMBR group from $98 \%$ to $1 \%$.

After 4 months from the operation, all crustations disappeared in nearly all patients. On the other hand, Cavaliere $\mathrm{M}$ et al., observed crustations at the end of first week in the group of inferior turbinectomy (mild in 14 patients, moderate in 6) but completely disappeared after 1 month. In the group of radiofrequency turbinoplasty, crustations was not observed [12]

Vijayakumar S., et al., [18] who had prospective study conducted on 30 adult patients with symptomatic hypertrophy of inferior turbinate not responded to medical treatment. All patients underwent surgical turbinoplasty. Crustations were seen in $40 \%$ of the patients at the end of 1 week followup, at the end of 1 month only 3 patients (10\%) and at 3 months, none had crusting. He informed that the time taken for the crusts to disappear is 13 months after surgical turbinoplasty.

In our study, post-operative nasal endoscopy was done on the regular post-operative visits. There was significant volume reduction in group A after one month of the operation "when crustations mostly disappeared". In group B, there was less significant volume reduction in the inferior turbinate at the three post-operative visits. More improvement was observed after two months. In group $\mathrm{C}$, there was significant decrease in the turbinate volume after disappearance of crustations.

From that previous results and after comparing our results with other national and international studies, we recommend more clinical trials with larger number with more outcomes as regard cost effectiveness of the variable modalities used in inferior turbinate volume reduction.

The post-operative assessment using MA-SNOT and nasal endoscopy revealed that patients in group A operated by endoscopic partial inferior turbinectomy has very good results regarding the subjective and objective measures with fear of atrophic rhinitis. Patients in group B operated by radiofrequency volume reduction had good results with recorded cases of step backing of MA-SNOT scores and endoscopic turbinate volume indicating the possibility of recurrence after volume reduction. This can give the impression that submucosal radiofrequency volume reduction better to be modulated to be more simple and under local anesthesia as an office procedure. We recommend further studies to compare between radiofrequency volume reduction under local and under general anesthesia.

Patients in group $\mathrm{C}$ operated by submucosal resection or turbinoplasty had also very good results with one obvious drawback which is relatively longer operative time. This could be related to the anesthetic pre-parations and more procedures were done to preserve as much as possible of the medial mucosal layer.

\section{Conclusion:}

We can conclude that there is no consensus on one surgical technique of the variable techniques of the inferior turbinate volume reduction. Partial inferior turbinectomy is one of the most frequent methods. It is better done with the endoscope to avoid leaving remnants and for better management of the bleeding points. Radiofrequency volume reduction using bipolar needle is good option to be done as an office-based technique and it can be repeated with recurrence. Turbinoplasty has better 
results as regarding post-operative crustations and MASNOT objective measure so it is good option but it takes more time. There is need for systematic reviews and meta-analysis as regarding these different techniques in inferior turbinate reduction.

\section{Conflicts of interest:}

No conflicts of interest declared.

\section{Authors' contributions:}

All authors had equal role in design, work, statistical analysis and manuscript writing.

\section{References}

1- NESKEY D., ELOY J.A., ROY R. and CASIANO R.R.: Nasal, Septal, and Turbinate Anatomy and Embryology. Otolaryngol. Clin. N. Am., 42: 193-205, 2009.

2- BERGER G., BALUM-AZIM M. and OPHIR D.: The normal inferior turbinate: histomorphometric analysis and clinical implications. Laryngo-scope, 113 (7): 11928, 2003.

3- KIZILKAYA Z., CEYLAN K., EMIR H., et al.: Comparison of radiofre-quency tissue volume reduction and submucosal resection with microdebrider in inferior turbinate hypertrophy. Otolaryngology-Head Neck Surgery, 138 (2): 176-81, 2008.

4- OSAMA MARGLANI A.A., TARIQ ABDUL FATTAH and ABDULMOHSEN AL-ZALABANI: The introduction and validation of a modified Arabic Sino-Nasal outcome test (MA-SNOT). Pan. Arab J. of Rhinol., 1, 2011.

5- PUTERMAN M., SEGAL N. and JOSHUA B.: Endoscopic, assisted, modified turbinoplasty with mucosal flap. The Journal of Laryngology \& Otology, 126 (05): 5258, 2012.

6- ELWANY S. and HARRISON R.: Inferior turbinectomy: Comparison of four techniques. The Journal of Laryngology \& Otology, 104 (03): 206-9, 1990.

7- CINGI C., URE B., CAKLI H. and OZUDOGRU E.: Microdebrider-assisted versus radiofrequency-assisted inferior turbinoplasty: A prospective study with objective and subjective outcome measures. Acta. Otorhinolaryngol. Ital., 30 (3): 138, 2010.

8- FRIEDMAN N.R.: Inferior turbinate reduction: An application for the microdebrider. Operative Techniques in
Otolaryngology-Head and Neck Surgery, 16 (4): 232-4, 2005.

9- GARZARO M., PEZZOLI M., PECORARI G., LANDOLFO V., DEFILIPPI S. and GIORDANO C.: Radiofrequency inferior turbinate reduction: An evaluation of olfactory and respiratory function. Otolaryngology--Head and Neck Surgery, 143 (3): 348-52, 2010.

10 - BUYUKLU F., CAKMAK O., HIZAL E. and DONMEZ F.Y. : Outfracture of the inferior turbinate: A computed tomography study. Plast. Reconstr. Surg., 123 (6): 17049, 2009.

11-PASSÀLI D., PASSÀLI F.M., PASSÀLI G.C., DAMIANI V. and BELLUSSI L.: Treatment of inferior turbinate hypertrophy: A randomized clinical trial. Ann. Otol Rhinol. Laryngol., 112 (8): 683-8, 2003.

12- CAVALIERE M., MOTTOLA G. and IEMMA M.: Comparison of the effectiveness and safety of radiofrequency turbinoplasty and traditional surgical technique in treatment of inferior turbinate hypertrophy. OtolaryngologyHead and Neck Surgery, 133 (6): 972-8, 2005.

13- LIU C.M., TAN C.D., LEE F.P., LIN K.N. and HUANG H.M.: Microdebrider-assisted versus radiofrequencyassisted inferior turbinoplasty. The Laryngoscope, 119 (2): 414-8, 2009

14- HAMERSCHMIDT R., HAMERSCHMIDT R., MOREIRA A.T.R., TENÓRIO S.B. and TIMI J.R.R.: Comparison of turbinoplasty surgery efficacy in patients with and without allergic rhinitis. Braz. J. Otorhinolaryngol., 82 (2): 131-9, 2016

15- MARKS S.: Endoscopic inferior turbinoplasty. Am. J Rhinol., 12 (6): 405-7, 1998.

16- MATHAI J.: Inferior turbinectomy for nasal obstruction review of 75 cases. Indian Journal of Otolaryngology and Head \& Neck Surgery, 56 (1): 23-6, 2004.

17- SAPÇI T., SAHIN B., KARAVUS A. and AKBULUT U.G.: Comparison of the effects of radiofrequency tissue ablation, $\mathrm{CO} 2$ laser ablation, and partial turbinectomy applications on nasal mucociliary functions. The Laryngoscope, 113 (3): 514-9, 2003.

18- VIJAYAKUMAR S. and DIVAKARAN S.: Role Of Surgical Turbinoplasty In The Management Of Inferior Turbinate Hypertrophy: A Case Series. Journal of Evolution of Medical And Dental Sciences-jemds, 4 (21): 3 655-61, 2015 . 


\section{مقارنة بين تقويم القرينة السفلية للآنف بإستخدام ترددات حرارية

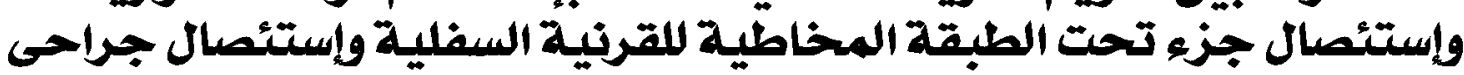

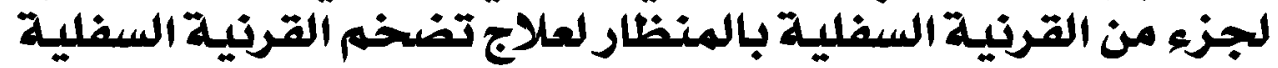

إنسداد الآنف هو واحد من شكاوى الآنف التى تزعج حياة الكثير من الناس فى العالم. يعد تضخم القرئة السفلية للآنف واحدة من الآسباب الآكثر شيوعا لإنسداد الآنف.

يمكن علاج هذه الحالة عن طريق العلاج الطبى مثل إستخدام عقار الكورتينون الموضعى ومضادات الهيستامين ومضادات الإحتقان لفترة من الوقت .

ومع ذلك، قد لا تكون هذه الألوية كافية للحد من حجم التضخم ذلك، وينبغى النظر فى تقنيات الجراحة بعد فشل العلاج الطبى.

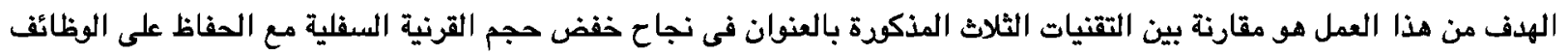

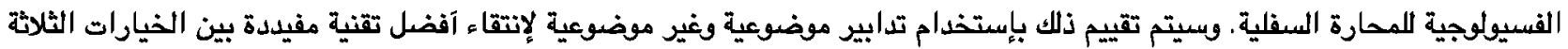

$$
\text { هذه الدراسة إستطلاعية وعشوائية ومزدوجة الآعماء آجريت على •10 مريض تم تقسيمهم إلى ب مجموعات. }
$$

يمكن آن نخلص إلى آنه لا يوجد توافق فى الآراء حل تقنية جراحية واحدة من التقنيات المتفيرة للتقليل من حجم القرنية السفلية. إستئصال القرنية السفلية جراحيا بالمنظار هى واحدة ممن الطرق الآكثر ثيوعا . فمن الآفضل القيام بها بالمنظار لتجنب ترك بقايا وإدارة آفضل لنقاط النزيف.

العلاج بالترددات الراديوية بإستخدام إبرة هو خيار جيد ليتم القيام به بإعتباره تقنية مؤثرة، ويمكن آن تككر مع تكرار حدوث تضخم القرنية

إستئصال الجزء العظمى لديه نتائج آفضل فيما يتعلق بقشور ما بعد الجراحة ومقياس سنوت كقياس موضوعى لذلك هو خيار جيد ولكن الآمر يستغرق المزيد من الوقت. 